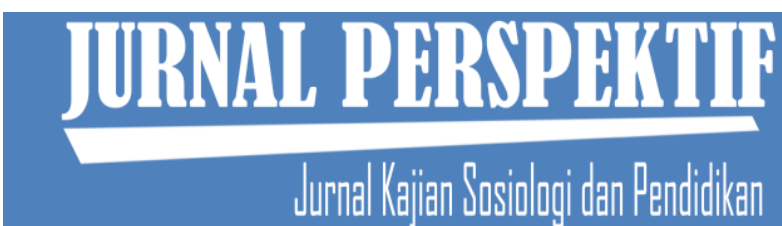

Jurnal Perspektif: Jurnal Kajian Sosiologi dan Pendidikan

Vol. 3 No. 1 Tahun 2020

http://perspektif.ppj.unp.ac.id

Email: perspektif@ppj.unp.ac.id

ISSN: 2622-1748 (Online), 2684-902X (Print)

DOI: http://dx.doi.org/10.24036/perspektif.v3i1.187

\title{
Gerakan Sosial Perempuan dalam Penolakan Pembangunan Pembangkit Listrik Tenaga Geothermal di Nagari Batu Bajangjang Kecamatan Lembang Jaya Kabupaten Solok
}

\author{
Suhai Ratu Rahmi ${ }^{1}$ Eka Vidya Putra ${ }^{2}$ \\ 1,2Universitas Negeri Padang \\ Email: suhairaturahmi@gmail.com, ekavidyaputra@fis.unp.ac.id
}

\begin{abstract}
Abstrak
Penelitian ini dilatar belakangi munculnya aktor penggerak perempuan dalam aksi penolakan pembangunan pembangkit listrik tenaga geothermal. Adapun tujuan dari penelitian ini untuk mengetahui alasan perempuan melanjutkan aksi penolakan. Teori yang digunakan contentious politics oleh Dough McAdam, Sydney Tarrow dan Charles Tilly. Metode penelitian yang digunakan kualitatif dengan tipe studi kasus jenis intrinsik dan pemilihan informan dengan teknik purposive sampling sebanyak 11 informan. Pengumpulan data dilakukan dengan cara observasi, wawancara dan dokumentasi serta menggunakan triangulasi pengamat dari Neuman. Teknik analisis data yang digunakan adalah teknik analisis data dari Miles dan Huberman (reduksi data, display data, dan penarikan kesimpulan). Hasil penelitian ini menunjukkan bahwa alasan perempuan melakukan aksi penolakan disebabkan oleh beberapa aspek yang mempengaruhi. Aspek tersebut, yaitu (1) Awal munculnya aksi penolakan (2) Perempuan sebagai aktor penggerak dalam aksi penolakan pembangunan geothermal: a) Mengurangi kekerasan, b) Hubungan kekerabatan, c) Tokoh kharismatik, d) Dukungan Lembaga Bantuan Hukum (LBH) Padang, e) Dukungan Masyarakat.

Kata kunci: Gerakan Sosial, Perempuan, Pembangkit Listrik Tenaga Geothermal
\end{abstract}

\section{Abstract}

This research is motivated by the emergence of female activists in the rejection of the construction of geothermal power plants. The purpose of this research is to find out the reasons why women continue the rejection action. Theories used contentious politics by Dough McAdam, Sydney Tarrow and Charles Tilly. The research method used is qualitative with an intrinsic type case study type and the selection of informants by purposive sampling technique as many as 11 informants. Data collection was carried out by observation, interview and documentation and using observer triangulation from Neuman. The data analysis technique used is the data analysis technique from Miles and Huberman (data reduction, data display, and drawing conclusions). The results of this study indicate that the reasons for women to resist are caused by several aspects that influence. These aspects, namely (1) Early emergence of the rejection action (2) Women as a driving actor in the rejection of geothermal development: a) Reducing violence, b) Kinship relations, c) Charismatic figures, d) Support of Legal Aid Institutions (LBH) Padang, e) Community Support.

Keywords: Social Movements, Women, Geothermal Power Plants

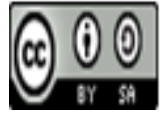

Received: January 10, $2019 \quad$ Revised: January 20, 2020 Available Online: January 21, 2020 
Suhai Ratu Rahmi, Eka Vidya Putra Gerakan Sosial Perempuan dalam penolakan Pembangunan Pembangkit Listrik Tenaga Geothermal di Nagari Batu Bajangjang, Kecamatan Lembang Jaya, Kabupaten Solok

\section{Pendahuluan}

Pembangunan seringkali diartikan sebagai suatu kegiatan yang terencana dilakukan demi mendapatkan perubahan ke arah yang lebih baik. pembangunan merupakan bagian dari aktivitas kehidupan manusia. Pembangunan diartikan sebagai pertumbuhan dan perubahan (Soekartawi, 1995). Konsep tentang pembangunan sebagai penggerakan sistem sosial yang mandeg, untuk mengejar tujuan-tujuan baru, makin menandaskan betapa pentingnya motivasi, tujuan, dan makna, dalam proses pembaharuan (Soedjatmoko, 1983). Tetapi pembangunan tidak selalu mendapatkan dukungan dari masyarakat. Adakala pembangunan mendapat penolakan dari masyarakat. Salah satu penolakan terjadi di Nagari Batu Bajangjang, Kecamatan Lembang Jaya, Kabupaten Solok.

Adapun penolakan yang terjadi dalam pembangunan pembangkit listrik tenaga geothermal di Gunung Talang. Penolakan tersebut berawal pada pertengahan tahun 2016, ketika Pemerintahan Nagari mengumumkan bahwa ada proyek pengembangan panas bumi di Gunung Talang. Hal ini membuat masyarakat terkejut akan pemberitahuan yang secara tibatiba tersebut (Hadi, Sastra Eril dan Putra, 2019). Perubahan Kelembagaan dari kerangka kelembagaan lama ke kelembagaan baru, mendapat respon tersendiri dari kalangan civil society (Amri et al., 2016). Penolakan masyarakat disampaikan dengan melakukan aksi massa turun kejalan. Aksi pertama dilakukan pada tanggal 13 September 2017. Masyarakat melakukan aksi penolakan dengan mendatangi kantor Bupati. Tuntutan masyarakat Cuma satu yakni penolakan pembangunan geothermal di wilayah Gunung Talang. Masyarakat yang hadir pada aksi tersebut sekitar 1000 (seribu) peserta.

Aksi kedua dilakukan pada tanggal 2 Oktober 2017, dengan jumlah peserta aksi lebih banyak lagi. Kali ini aksi yang dilakukan tidak berjalan dengan mulus. Ditengah jalannya aksi terjadi kericuhan dimulai ketika pengunjuk rasa nekad menerobos pengamanan yang dilakukan petugas gabungan. Masyarakat yang terkonsentrasi di Tugu Ayam membawa sejumlah spanduk dan pamflet bertuliskan penolakan pembangunan pembangkit listrik tenaga geothermal. Dalam orasinya masyarakat yang mewakili 12 Nagari di selingkar Gunung Talang. Massa juga mengancam akan memaksa masuk ke dalam komplek kantor Bupati, jika Bupati Solok tidak mau menemui masyarakat. Untuk mengamankan aksi ini, ratusan personel gabungan TNI, Polres Arosuka, Satpol PP disiapkan untuk berjaga-jaga. Masyarakat yang kecewa karena belum juga melihat Bupati datang, akhirnya nekad bersama-sama untuk menerobos personel keamanan agar bisa langsung bertemu dengan Bupati. Terjadi aksi dorong antar masyarakat dengan jajaran gabungan TNI, Polres Arosuka, Polres Solok Kota, Satpol PP yang sedang berjaga-jaga. Kericuhan tidak terkendalikan lagi hingga terjadi lempar batu dan pasir yang mengarah kepada tim gabungan keamanan, kemudian terjadi perkelahian antar demonstran dengan petugas serta terjadi peristiwa pembakaran mobil. Ujung dari aksi 2 Oktober 2017 adalah penangkapan aktor penggerak dari aksi penolakan pembangunan akibat peristiwa pembakaran mobil aparat. Diantara aktor penggerak yang ditangkap yaitu Yuzawerdi, Ayu Dasril dan Hendra serta 12 orang yang menjadi daftar pencarian orang (DPO).

Secara fisik aksi pada tanggal 2 Oktober 2017 aktor penggerak sebelumnya dipenjara dan sebagian menjadi daftar pencarian orang (DPO). Secara phiskis, masyarakat Gunung Talang sendiri mengalami intimidasi dan mendapat ancaman dari berbagai pihak. Tetapi kondisi tersebut tidak mempengaruhi untuk melakukan aksi serupa. Masyarakat terus menyuarakan penolakan, lebih menarik kali ini aktor dari gerakan tersebut adalah kelompok perempuan. Setidaknya terdapat sejumlah aktor kunci perempuan yakni: 
Tabel 1. Perempuan Yang Menjadi Aktor Penggerak Dalam Aksi Penolakan Pembangunan Geothermal Di Nagari Batu Bajangjang

\begin{tabular}{cc}
\hline Nama & Umur \\
\hline Buk As & 67 Tahun \\
\hline Indah & 24 Tahun \\
\hline Buk Ita & 48 Tahun \\
\hline Buk Epi & 50 Tahun \\
\hline Yulita & 38 Tahun \\
\hline Fatmawati & 35 Tahun \\
\hline Erlina & 46 Tahun \\
\hline Asmelia & 49 Tahun \\
\hline Sidarna & 44 Tahun \\
\hline Dila Safitri & 24 Tahun \\
\hline
\end{tabular}

Sumber: Lembaga Bantuan Hukum (LBH) Padang

Kenapa perempuan mengambil alih aksi penolakan pembangunan pembangkit listrik tenaga geothermal menarik untuk diteliti lebih dalam. Realitas pada saat ini adalah perempuan dianggap sebagai sosok yang lembut dan hanya pada sektor domestik. Penelitian yang relevan dengan penelitian ini adalah penelitian yang dilakukan oleh Annisa Innal Fitri, Idil Akbar berjudul "Gerakan Sosial Perempuan Ekofeminisme di Pegunungan Kendeng Provisnsi Jawa Tengah Melawan Pembangunan Tambang Semen”yang menjelaskan bahwa gerakan sosial perempuan dapat berperan strategis untuk menguatkan geraka-gerakan perlawanan masyarakat, sebagai agen untuk memperjuangkan hak-hak demokratis, keadilan dan pembebasan rakyat (Fitri \& Akbar, 2017). Penelitian Dia Puspitasari berjudul "Gerakan Perempuan Melawan Korporasi Tambang (Studi Perspektif Gender di Pegunungan Kendeng Utara, Kecamatan Gunem, Kabupaten Rembang, Provinsi Jawa Tengah) yang menjelaskan bahwa gerakan dan strategi yang digunakan oleh ibu-ibu dalam menjaga kelestarian alam di lereng Pegunungan Kendeng Utara, Kecamatan Rembang, Kabupaten Rembang, Jawa Tengah (Puspitasari, 2013). Penelitian Leni Liberti, Erda Fitriani, Eka Vidya Putra berjudul “ Keterlibatan Mahasiswa dalam Aksi Bela Islam 212 di Jakarta” yang menjelaskan keterlibatan mahasiswa jika dilihat jarak antara Padang dengan Jakarta tidak dekat, mereka pergi dengan resiko yang cukup besar tidak ada yang bertanggung jawab atas keselamatan mereka, ada kemungkinan hal-hal yang tidak diinginkan terjadi. Untuk sampai ke Jakarta harus berkorban tidak hanya secara fisik maupun materi dan meninggalkan aktivitas perkuliahan (Liberti, Leni, Fitriani, Erda, Putra, 2019).

Semua penelitian terdahulu memiliki persamaan dengan penelitian peneliti yaitu sama-sama membahas tentang gerakan-gerakan yang dilakukan perempuan dalam menentang kebijakan Pemerintah. Sedangkan perbedaan dalam penelitian Annisa Innal Fitri, Idil Akbar adalah perempuan dapat berperan strategis untuk menguatkan gerakan-gerakan perlawanan masyarakat, penelitian Dia Puspita Sari menjelaskan perempuan sebagai strategi dari sebuah gerakan dan penelitian Leni Liberti, Erda Fitriani, Eka Vidya Putra menjelaskan alasan yang mendorong seseorang untuk terlibat dalam sebuah gerakan bersama untuk memperbaiki 
Suhai Ratu Rahmi, Eka Vidya Putra Gerakan Sosial Perempuan dalam penolakan Pembangunan Pembangkit Listrik Tenaga Geothermal di Nagari Batu Bajangjang, Kecamatan Lembang Jaya, Kabupaten Solok

situasi (Liberti, Leni, Fitriani, Erda, Putra, 2019). Sedangkan Pada penelitian peneliti tentang perempuan sebagai aktor penggerak dalam aksi penolakan, maka studi penelitian peneliti adalah alasan perempuan menjadi aktor penggerak dalam penolakan pembangunan pembangkit listrik tenaga geothermal di Nagari Batu Bajangjang, Kecamatan Lembang Jaya, Kabupaten Solok.

\section{Metode Penelitian}

Jenis penelitian yang dipilih merupakan pendekatan kualitatif, karena permasalahan dalam penelitian ini bersifat kompleks, dinamis dan penuh makna, sehingga bermaksud untuk memahami situasi sosial secara mendalam (Moleong, 2002). Fokus dalam penelitian ini melihat gerakan sosial perempuan dalam penolakan pembangunan geothermal. Tipe penelitian yang digunakan dalam penelitian ini adalah tipe studi kasus. Studi kasus merupakan rancangan penelitian yang mengembangkan analisis mendalam terhadap suatu kasus. Kasus-kasus dibatasi oleh waktu dan aktivitas serta peneliti mengumpulkan informasi secara lengkap dengan memakai beragam prosedur pengumpulan data berdasarkan waktu yang telah ditentukan (w. creswell, 2016). Tipe studi kasus yang digunakan adalah tipe studi kasus instrinsik, studi kasus instrinsik menekankan pada pemahaman (Verstehen) yang mendalam namun tidak dimaksudkan untuk memahami fenomena umum yang bisa di generalisasikan, tapi lebih mementingkan kepentingan intrinsik dan tidak dimaksudkan untuk membentuk teori baru (Idrus, 2009).

Lokasi penelitian dilakukan di Nagari Batu Bajangjang, Kecamatan Lembang Jaya, Kabupaten Solok. Alasannya karena sebagian besar perempuan disana yang aktif sebagai aktor penggerak dari gerakan sosial dalam aksi penolakan. Pemilihan informan penelitian memakai teknik purposive sampling. Alasan peneliti menggunakan teknik ini karena peneliti sudah memiliki pemetaan terhadap orang yang akan dijadikan informan. Informan dalam penelitian ini adalah perempuan yang berperan sebagai aktor penggerak dari gerakan sosial perempuan dalam penolakan pembangunan geothermal, serta masyarakat yang ikut terlibat dalam aksi. Total informan mencapai 11 (sebelas) orang informan, dengan rincian 10 (sepuluh) orang perempuan yang menjadi aktor penggerak dan 1 (satu) orang masyarakat yang terlibat dalam aksi penolakan.

Teknik pengumpulan data dilakukan pada natural setting (kondisi yang alamiah), sumber data primer, dan teknik pengumpulan data lebih banyak pada observasi berperan serta (partisipant observasion), wawancara mendalam (in depth interview) dan dokumentasi (Sugiyono, 2017). Dalam penelitian ini, peneliti menggunakan teknik pengumpulan data observasi, wawancara dan dokumentasi. Observasi (pengamatan) yang digunakan dalam penelitian ini adalah observasi partisipasi pasif. Dalam hal ini peneliti datang ke tempat kegiatan yang diamati, tetapi tidak ikut terlibat dalam kegiatan tersebut (Sugiyono, 2017). Dalam hal ini peneliti mengamati gerakan sosial perempuan dalam penolakan pembangunan pembangkit listrik tenaga geothermal. Setelah melakukan observasi peneliti melakukan wawancara dengan subjek penelitian yaitu dengan aktor penggerak perempuan dalam aksi penolakan dan pihak yang terlibat dalam aksi tersebut. Selain observasi dan wawancara, peneliti juga menggunakan berbagai dokumen dalam menjawab pertanyaan terarah. Studi dokumen merupakan pelengkap dari penggunaan metode observasi dan wawancara dalam penelitian.

Analisis data merupakan suatu penyusunan data agar data tersebut dapat ditafsirkan. Menyusun data berarti mengelompokkan dalam pola atau kategori sedang tafsiran atau interpretasi artinya memberikan makna pada analisa dalam menjelaskan pola atau kategori dalam mencari hubungan antar berbagai konsep (w. creswell, 2016). Reduksi data merupakan 
proses pemilihan, pemusatan perhatian pada penyederhanaan, pengabstrakan dan transformasi data kasar yang muncul dilapangan. Pengabstrakan yang dimaksud dalam penelitian ini adalah membuat rangkuman (menajamkan, menggolongkan, mengarahkan serta membuang yang tidak perlu) proses penelitian mengenai gerakan sosial perempuan dalam penolakan pembangunan pembangkit listrik tenaga geothermal. Penyajian data atau display data merupakan penyajian data secara sederhana yang dapat mempermudah dalam penarikan kesimpulan. Penyajian data ini diperlukan agar tidak meyimpang dari pokok permasalahan. Penarikan kesimpulan dilakukan untuk mengumpulkan data-data hasil wawancara dan observasi mengenai alasan perempuan melakukan aksi penolakan pembangunan pembangkit listrik tenaga geothermal.

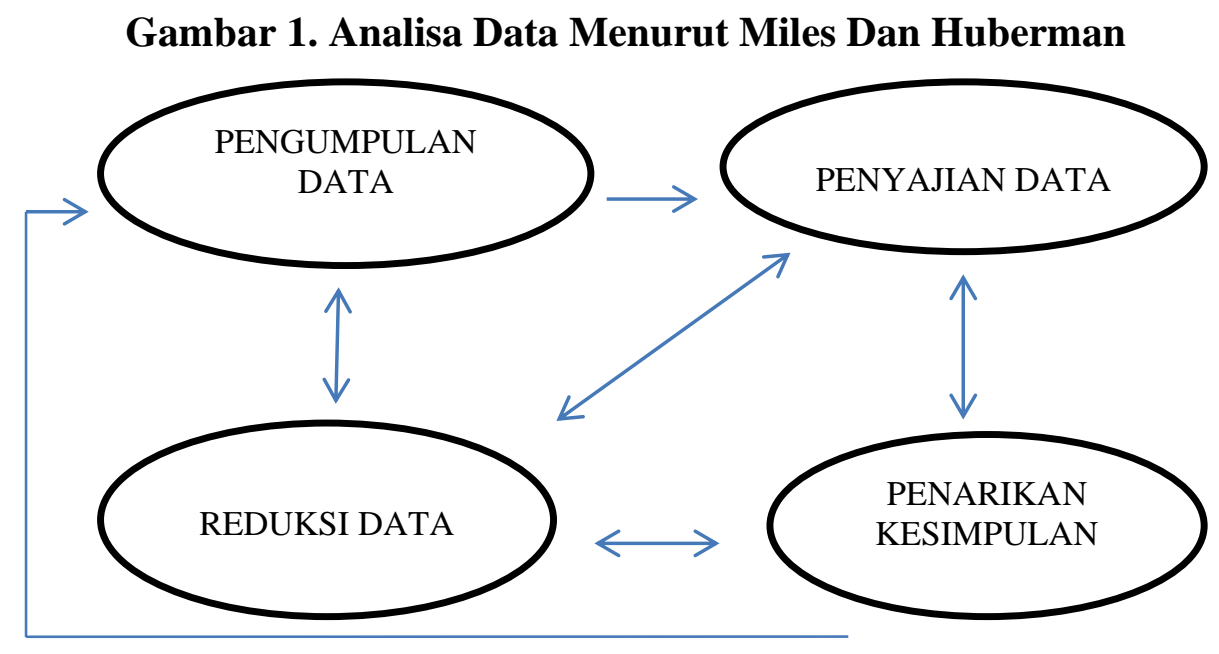

\section{Hasil dan Pembahasan}

Gerakan sosial merupakan sebuah gerakan yang dilakukan secara bersama untuk mencapai tujuan yang diinginkan. Gerakan sosial lahir dari situasi masyarakat karena adanya ketidakadilan dan sikap sewenang-wenang terhadap masyarakat. Berdasarkan atas penelitian terkait dengan gerakan sosial perempuan dalam penolakan pembangunan pembangkit listrik tenaga geothermal di Nagari Batu Bajangjang, Kecamatan Lembang Jaya, Kabupaten Solok, yakni:

Awal Munculnya Aksi Penolakan, rencana pembangunan pembangkit listrik tenaga geothermal diketahui ketika pihak perusahaan datang melakukan sosialisasi ke Pemerintah Daerah. Saat itu ada beberapa masyarakat yang datang karena penasaran dengan apa yang akan di bangun di Gunung Talang dan menghadiri pertemuan tersebut walaupun tidak diundang. Pada bulan Juli 2017, masyarakat baru mengetahui ada pembangunan pembangkit listrik tenaga geothermal di Nagari Batu Bajangjang, Kecamatan Lembang Jaya, Kabupaten Solok. Ketidakpuasan yang mereka rasakan adalah ketika mempertanyakan dampak negatif kepada pihak perusahaan tetapi direspon dengan jawaban yang tidak pantas sehingga menimbulkan rasa curiga masyarakat. Hal ini membuat masyarakat merasa Pemerintah maupun perusahaan melakukan intimidasi yang kuat. Sehingga pada tanggal 13 September 2017 mengadakan aksi yang diikuti oleh 1000 (seribu) peserta. Aksi kedua dilakukan pada 2 Oktober 2017 dengan massa yang lebih banyak lagi. Kali ini aksi mengalami kericuhan yang berujung pada peristiwa pembakaran mobil dan penangkapan sejumlah aktor penggerak dan sebagian sebagai daftar pencarian orang (DPO).

Perempuan Sebagai Aktor Penggerak Dalam Aksi Penolakan Pembangunan Geothermal, perempuan seringkali dianggap sebagai sosok yang lemah dan hanya Jurnal Perspektif: Jurnal Kajian Sosiologi dan Pendidikan Vol. 3, No. 1, Th. 2020 
mengerjakan pekerjaan pada sektor domestik. Tetapi ada aspek-aspek tertentu yang membuat perempuan melakukan hal-hal diluar dugaan, seperti perempuan yang ada di Nagari Batu Bajangjang, Kecamatan Lembang Jaya, Kabupaten Solok. Perempuan tersebut menjadi aktor penggerak dari sebuah aksi penolakan. Hal ini terjadi karena ada beberapa faktor yang mempengaruhi, yakni:

Mengurangi Kekerasan, pada tanggal 2 Oktober 2017 terjadi aksi unjuk rasa yang mengklaim 12 Nagari di Selingkar Gunung Talang. Massa bahkan sempat mengancam untuk memaksa masuk ke dalam kompleks kantor Bupati, jika Bupati Solok tidak mau menemui masyarakat. Untuk mengamankan aksi ini, ratusan personel gabungan dari TNI, Polres Arosuka, Satpol PP disiapkan untuk berjaga-jaga. Masyarakat yang kecewa karena belum juga melihat Bupati datang, akhirnya nekad bersama-sama untuk menerobos personel keamanan agar bisa langsung bertemu dengan Bupati. Terjadi aksi saling dorong antara masyarakat dengan jajaran gabungan TNI, Polres Arosuka, Polres Solok Kota, Satpol PP yang sedang berjaga-jaga. Kericuhan tidak terkendalikan lagi hingga terjadinya lempar batu dan pasir yang mengarah pada tim gabungan keamanan, kemudian terjadi perkelahian antara demonstran dengan petugas serta terjadi peristiwa pembakaran mobil. Kericuhan yang tidak terkendali membuat masyarakat berada dalam situasi yang tidak stabil dan hal tersebut harus dihindarkan agar tidak terulang lagi. Untuk mengatasi situasi seperti ini harus dibangun strategi untuk mengurangi resiko kekerasan yang terjadi.

Hubungan Kekerabatan, keterlibatan perempuan dalam aksi penolakan pembangunan geothermal dipicu oleh salah satu faktor yaitu hubungan kekerabatan. Semenjak peristiwa penangkapan aktor penggerak dari laki-laki muncul aktor penggerak perempuan yang melanjutkan perjuangan. Perempuan mengambil alih posisi paling depan dalam aksi tersebut dan perempuan yang menjadi aktor penggerak merupakan orang-orang terdekat dari pihakpihak yang telah dirugikan. Tokoh Kharismatik, salah satu faktor pendorong perempuan di Nagari Batu Bajangjang, Kecamatan Lembang Jaya, Kabupaten Solok ikut berperan aktif dalam aksi penolakan pembangunan geothermal ialah karena ada dorongan yang kuat dari tokoh yang selalu memberikan motivasi untuk melanjutkan perjuangan. Ada 10 (sepuluh) perempuan yang menjadi aktor penggerak dalam aksi tersebut. Salah satu diantara mereka berperan sebagai bundo kanduang di Kecamatan Lembang Jaya. Beliau dianggap sebagai tokoh kharismatik bagi masyarakat di sekitar Gunung Talang, apapun perkataan dan ajakannya selalu diikuti oleh masyarakat, meskipun dia sudah tua tetapi tetap semangat untuk mengayomi masyarakat, padahal sudah seringkali mendapat ancaman dari pihak tidak dikenal akan dibunuh. Tetapi ia tidak pernah takut dan justru karena hal tersebut membuatnya lebih semangat lagi dalam mendampingi masyarakat melakukan aksi penolakan pembangunan geothermal.

Dukungan Lembaga Bantuan Hukum (LBH) Padang, dukungan dari LBH Padang dimulai ketika masyarakat mendengar kabar akan ada pembangunan geothermal. Kemudian beberapa perwakilan masyarakat Gunung Talang datang ke LBH untuk melakukan konsultasi hukum. Kosnsultasi hukum yang dilakukan tentang apa yang tidak mereka ketahui tentang geothermal dan apa yang harus dilakukan. LBH mengarahkan masyarakat untuk mengikuti sosialisasi yang dilakukan oleh Pemerintah dan perusahaan, agar masyarakat dapat mempertanyakan soal pembangunan serta meyakinkan masyarakat bahwa proses pembangunan harus mendapat persetujuan sukarela dari masyarakat sebagaimana yang dilakukan secara universal. Setelah sosialisasi dilakukan masyarakat datang kembali ke LBH dan mengatakan ketidakpuasan mereka terhadap sosialisasi yang dilakukan oleh perusahaan dan Pemerintah. Dukungan Masyarakat, dukungan masyarakat ialah bentuk perhatian, 
penghargaan, penerimaan, maupun pertolongan dalam bentuk lainnya yang berasal dari orang yang memiliki hubungan sosial dekat. Gerakan sosial perempuan dalam penolakan pembangunan geothermal mendapat dukungan dari masyarakat di Kecamatan Lembang Jaya, Kabupaten Solok. Seperti temuan peneliti dilapangan, pada saat memperingati hari tani pada tanggal 24 September 2019 seluruh masyarakat ikut berpartisipasi untuk memperingatinya, mereka membawa hasil ladang dan properti yang digunakan saat berladang. Masyarakat sangat antusias untuk mengikuti segala kegiatan yang berkaitan dengan penolakan pembangunan geothermal.

\section{Kesimpulan}

Gerakan Sosial merupakan suatu aksi perlawanan yang dilakukan secara bersama-sama untuk mencapai tujuan bersama. Gerakan perlawanan ini dapat melibatkan siapa saja termasuk perempuan seperti aksi penolakan yang dilakukan oleh perempuan di Nagari Batu Bajangjang, Kecamatan Lembang Jaya, Kabupaten Solok. Gerakan sosial perempuan dalam sebuah aksi menurut Dough McAdam, Sydney Tarrow dan Charles Tilly melalui teori Contentious politics yang dikembangkan. Terdapat 3 (tiga) mekanisme gerakan sosial (Situmorang, 2007). Pertama, mekanisme struktur ancaman politik yang terdapat di Gunung Talang adalah ketika masyarakat mengetahui ada rencana pembangunan geothermal.

Kedua, mekanisme peranan perantara dalam gerakan sosial perempuan dalam penolakan pembangunan geothermal adalah LBH Padang yang selalu memberi dukungan kepada perempuan untuk tidak takut bergabung dalam sebuah gerakan perlawanan. Terakhir, peran simbolisasi perlawanan dalam penolakan pembangunan berjumlah 10 (sepuluh) orang perempuan. Salah satunya berperan sebagai Bundo Kanduang di Kecamatan Lembang Jaya, Kabupaten Solok. Ia dianggap sebagai tokoh kharismatik bagi masyarakat. Meskipun seringkali mendapat ancaman akan dibunuh dari orang yang tidak dikenal tetapi beliau tidak pernah takut dan terus mengayomi masyarakat dalam melakukan aksi penolakan.

\section{Daftar Pustaka}

Mujiburrahman, Abidin, M Zainal \& Rahmadi (2012). Ulama Banjar Kharismatik Masa Kini di Kalimantan Selatan: Studi Terhadap Figur Guru Bachiet, Guru Danau, Dan Guru Zuhdi. Al-Banjari: Jurnal Ilmiah Ilmu-Ilmu Keislaman, 11(2), 65-68. https://doi.org/10.18592/al-banjari.v11i2.421

Amri, E., Putra, E. V., \& Fernandes, R. (2016). Pola Hubungan Negara dan Civil Society Patterns State and Civil Society Relations. Jurnal Kajian Politik Dan Masalah Pembangunan, 12(2), 1821-1828. https://media.neliti.com/media/publications/125806ID-pola-hubungan-negara-dan-civil-society.pdf

Fitri, A. I., \& Akbar, I. (2017). Gerakan Sosial Perempuan Ekofeminisme di Pegunungan Kendeng Provinsi Jawa Tengah Melawan Pembangunan Tambang Semen. CosmoGov, 3(1), 83. https://doi.org/10.24198/cosmogov.v3i1.12634

Ghofur, Abdul; Susilo, S. (n.d.). Perempuan dan Narasi Kekerasan: Studi Kritis Peran Gender dalam Deradikalisasi. Jurnal Tasawuf dan Pemikiran Islam, 5(2), 431-454.

Hadi, ES dan Putra, E.V. (2019). Resistensi Masyarakat Terhadap Rencana Pembangunan PLTP (Pembangkit Listrik Tenaga Panas Bumi) di Gunung Talang Kabupaten Solok. Jurnal Perspektif, 2(4), 236 244. https:// perspektif.ppj.unp.ac.id.

Hassan, A. (1972). Struktur Famili dan Tingkah laku Kekeluargaan di Selemak: Satu Kajian Kes. Akademika, 1(1), 3-5.

Idrus, M. (2009). Metode Penelitian Ilmu Sosial. Yogyakarta: Erlangga.

Lasmadi, S. (2014). Peran Advokat dalam Pendampingan Hukum. Inovatif, VII(II), 59-75. 
https://media.neliti.com/media/publications/43209-ID-peran-advokat-dalampendampingan-hukum.pdf

Liberti, L, Fitriani, E, Putra, E.V. (2019). Keterlibatan Mahasiswa dalam Aksi Bela Islam 212 di Jakarta. Jurnal Perspektif, 1(4), 22-26. https://perspektif.unp.ppj.ac.id

Machya Astuti Dewi. (2009). Media Massa dan Penyebaran Isu Perempuan. Jurnal Ilmu Komunikasi, 7(2), 228-236.

Moleong, L. . (2002). Metode Penelitian Kualitatif. Bandung: Rosdakarya.

Puspitasari, D. (2013). Gerakan Perlawanan dalam Melawan Korporasi Tambang. Journal of Chemical Information and Modeling, 53(9), 1689-1699.

Situmorang, A. W. (2007). Gerakan Sosial. Yogyakarta: Pustaka Belajar.

Soedjatmoko. (1983). Dimensi Manusia dalam Pembangunan. Jakarta: PT. Pustaka LP3ES Indonesia.

Soekartawi. (1995). Pembangunan Pertanian. Jakarta: PT. Raja Grafindo Persada.

Sugiyono. (2017). Metode Penelitian Kuantitatif, Kualitatif dan R\&D. Bandung: Alfabeta.

Susilo, D., \& Kodir, A. (2016). Politik Tubuh Perempuan: Bumi, Kuasa, dan Perlawanan. Jurnal Politik, 1(2). https://doi.org/10.7454/jp.v1i2.19

W. Creswell, J. (2016). Research Design, Pendekatan Metode Kualitatif, Kuantitatif dan Campuran. Yogyakarta: Pustaka Belajar. 